\title{
What factors influence UK medical students' choice of foundation school?
}

This article was published in the following Dove Press journal:

Advances in Medical Education and Practice

20 April 2017

Number of times this article has been viewed

\author{
Saiful Miah ${ }^{1,2}$ \\ Karl H Pang ${ }^{3}$ \\ Wayne Rebello ${ }^{4}$ \\ Zoe Rubakumar ${ }^{4}$ \\ Victoria Fung ${ }^{5}$ \\ Suresh Venugopal ${ }^{6}$ \\ Hena Begum ${ }^{4}$ \\ 'Division of Surgery and \\ Interventional science, University \\ College London, London, UK; \\ ${ }^{2}$ Department of Urology, Charing \\ Cross Hospital Imperial College \\ Healthcare NHS Trust, London, UK; \\ ${ }^{3}$ Academic Urology Unit, University \\ of Sheffield, Sheffield, UK; ${ }^{4}$ Medical \\ School, University of Sheffield, \\ Sheffield, UK; ${ }^{5}$ Department of Plastic \\ Surgery, Royal Hallamshire Hospital, \\ Sheffield, UK; ${ }^{6}$ Department of \\ Urology, Chesterfield Royal Infirmary, \\ Chesterfield, UK
}

Correspondence: Saiful Miah

Division of Surgery and Interventional

Science, University College London,

2I University Street, London, WCIE

6AU, UK

Email saiful.miah@ucl.ac.uk
Background: We aimed to identify the factors influencing UK medical student applicants' choice of foundation school. We also explored the factors that doctors currently approaching the end of their 2-year program believe should be considered.

Methods: A cross-sectional study was conducted during the 2013-2014 academic year. An online questionnaire was distributed to 2092 final-year medical students from nine UK medical schools and 84 foundation year-2 (FY2) doctors from eight foundation schools. Participants were asked to rank their top 3 from a list of 12 factors that could potentially influence choice of foundation school on a 5-point Likert scale. Collated categorical data from the two groups were compared using a chi-square test with Yates correction.

Results: Geographic location was overwhelmingly the most important factor for medical students and FY2 doctors with $97.2 \%$ and $98.8 \%$ in agreement, respectively. Social relationships played a pivotal role for medical student applicants. Clinical specialties within the rotations were of less importance to medical students, in comparison to location and social relationships. In contrast, FY2 doctors placed a significantly greater importance on the specialties undertaken in their 2-year training program, when compared to medical students (chi-square; $p=0.0001$ ).

Conclusion: UK medical schools should make their foundation program applicants aware of the importance of choosing rotations based on specialties that will be undertaken. Individual foundation schools could provide a more favorable linked application system and greater choice and flexibility of specialties within their 2-year program, potentially making their institution more attractive to future applicants.

Keywords: foundation school, UK postgraduate training, location of training, social relationships

\section{Introduction}

In 2005, the UK Department of Health introduced Modernising Medical Careers, a new program for postgraduate medical training. ${ }^{1}$ The foundation program comprises the first 2 years of UK postgraduate medical training, consisting of six 4-month blocks of different specialties. The aim of the foundation program was to create a generic training curriculum with successful completion of foundation year 1 (FY1) and foundation year 2 (FY2) being competency based. This was to form a bridge between medical school and specialist/general practice training, allowing foundation doctors to develop and demonstrate a range of transferable essential interpersonal and clinical skills for managing both acute and chronic conditions, regardless of specialty. At present, the combination of specialties within a foundation program is chosen from a fixed preset list, which an applicant selects with little opportunity to alter once entered. 
Reputation and prestige have been shown to be a primary factor influencing the choice of medical school for undergraduate applicants. ${ }^{2}$ Factors influencing medical students and early graduates regarding their career choice have been extensively studied. Clinical and personal mentors, lifestyle, prestige and interest all appear to be influencing factors in the future career choices of medical students globally. ${ }^{3-8}$ The UK postgraduate medical training is unique in that it requires all graduates to complete a generic 2-year program prior to applying for specialist training in their chosen career pathway.

Since the introduction of the foundation program, the factors influencing students' choice of foundation schools and their subsequent views of their choices on completion of foundation training are unclear, with only two such studies addressing this., ${ }^{910}$ This information would be of value to foundation schools, as they could potentially tailor their individual programs to attract a greater number of applicants based on their preferences. There is evidence that due to the current UK junior doctor contract changes, up to $70 \%$ of medical graduates will consider leaving the UK health system. ${ }^{11}$ Workforce planning is a core issue for service provision and has a direct impact on medical education. ${ }^{12}$ Regional health services require sufficient medical graduates to train in all specialties and in the right proportions to address local health care needs. ${ }^{13}$ It has been suggested that this distribution should be undertaken at the medical school selection stage and throughout undergraduate training, rather than after graduation..$^{13}$ Here, we provide an analysis of factors that influence foundation school choice with undergraduate medical students. We also explore which factors future applicants should be taking into consideration when applying to the foundation school, as advised by those doctors approaching the end of their foundation training program.

\section{Methods Study design}

We performed a descriptive cross-sectional study during the academic year 2013-2014. Our defined population consisted of final-year students in UK medical schools and FY2 doctors who were in their last placement of the 2-year foundation program.

\section{Participants}

All final-year medical students (academic year of 2013-2014) from nine UK medical schools (Edinburgh, Swansea, Imperial, Peninsula, Leicester, Keele, Sheffield, Liverpool and Glasgow [N=2092]) were invited to complete an online questionnaire.
Eighty-four FY2 doctors in eight foundation schools (Yorkshire and the Humber, London, Trent, Northern, West Midlands, Trent, Mersey and East Anglia), all of whom were in their final 4-month placement (2015), were also invited to complete a questionnaire.

The study was granted approval by our local ethics committee (University of Sheffield Medical School). The informed consent details the study explained to participants, the study's nature, format and the reasons behind the study. Completion of the questionnaire was deemed to be consent to participate in the study. Study participants were made aware that the collected data were intended for publication and presentation. Ethical issues with regard to data security were addressed by using a secure cloud-based access system.

\section{Data collection method}

The methods are reported in accordance with the Checklist for Reporting Results of Internet Surveys. ${ }^{14}$ The instruments used in our study were two 15 -item questionnaires. As no existing instrument was validated to evaluate our study aims, the questions were developed based on literature review and factors previously identified as influential on future foundation school choice from studies published in peer-reviewed journals. ${ }^{9,10}$ We first piloted our study in our home institution (University of Sheffield) to ensure face validity and clarity.

The two 15-item questionnaires were created using an online survey tool and sent to an academic or institutional contact within each medical school or foundation school. These individual questionnaires were distributed via a weblink to the relevant parties. Anonymous responses were completed on this online survey tool. Questions 1-12 used a 5-point Likert scale (1: strongly agree, 2 : agree, 3 : neither agree nor disagree, 4 : disagree and 5: strongly disagree) to assess final-year medical students' and FY2 doctors' views of the 12 factors which influenced/should influence the choice of foundation school (location, partner, financial, family, friends, prestige, choice of specialties in FY1, choice of specialties in FY2, undergraduate experience, recommendation, availability of academic post and perceived competitiveness). Question 13 asked all participants to select the most important factor that influenced/should influence the choice of foundation school. Question 14 asked all participants to select the second most important factor that influenced/should influence the choice of foundation school. Question 15 asked all participants to select the third most important factor that influenced/should influence the choice of foundation school. 


\section{Data analysis}

Questionnaire responses were entered into an SPSS database (SPSS Version 21). We created a cumulative ranking score (CRS) for the top three factors influencing final-year medical students and FY2 doctors. This was achieved using a formula giving a higher weighting to the first factor (multiplied by 3 ) and the second factor (multiplied by 2), compared to the third factor:

\section{$\mathrm{CRS}=(3 \times$ first factor $)+(2 \times$ second factor $)+$ third factor}

Categorical data regarding agreement (strongly agree or agree) of influencing factors and CRS between the two groups were compared using a chi-square test with Yates correction. A $p$-value of $<0.05$ was considered to be significant.

\section{Ethical approval}

The study was approved by the University of Sheffield Medical School ethics committee (SMBRER300).

\section{Results}

In total, we received complete responses from 361 (response rate $=361 / 2092$ [17.3\%]) medical students and all 84 FY2 doctors. A comparison of the responses and CRS for the 12 influencing factors between medical students and FY2 doctors is summarized in Tables 1 and 2.

Almost all medical students and FY2 doctors $(97.2 \%$ and $98.8 \%$, respectively) were in agreement that geographic location was important when choosing a foundation school. With regard to family, $62.3 \%$ and $79.8 \%$ of medical students

Table I A comparison between the number of final-year medical students and FY2 doctors in agreement (agreement defined as selecting strongly agree or agree on Likert scale) with each factor

\begin{tabular}{|c|c|c|c|c|c|}
\hline \multirow[t]{2}{*}{ Factor } & \multicolumn{2}{|c|}{ Medical students } & \multicolumn{2}{|c|}{ FY2 doctors } & \multirow[t]{2}{*}{$p$-value } \\
\hline & $\mathbf{n}$ & $\%$ & $\mathbf{n}$ & $\%$ & \\
\hline Specialties in FYI & 157 & 43.5 & 67 & 79.8 & 0.0001 \\
\hline Specialties in FY2 & $|7|$ & 47.4 & 72 & 85.7 & 0.0001 \\
\hline $\begin{array}{l}\text { Undergraduate } \\
\text { experience }\end{array}$ & 244 & 67.5 & 55 & 65.4 & 0.404 \\
\hline Prestige & 145 & 40.1 & 32 & 38.1 & $0.41 \mathrm{I}$ \\
\hline $\begin{array}{l}\text { Perceived } \\
\text { competitiveness }\end{array}$ & 191 & 52.9 & 37 & 44.1 & 0.090 \\
\hline Academic & 56 & 15.5 & 42 & 50 & 0.0001 \\
\hline Location & 351 & 97.2 & 83 & 98.8 & 0.327 \\
\hline Family & 225 & 62.3 & 67 & 79.8 & 0.002 \\
\hline Partner & 188 & 52 & 72 & 85.7 & 0.000 \\
\hline Friends & 220 & 55.4 & 64 & 76.1 & 0.006 \\
\hline Finance & 158 & 43.8 & 60 & 71.5 & 0.0001 \\
\hline Recommendations & 225 & 62.4 & 67 & 79.8 & 0.002 \\
\hline
\end{tabular}

Note: $p$-value (chi-square test).

Abbreviations: FYI, foundation year I; FY2, foundation year-2.
Table 2 A comparison of CRS between final-year medical students and FY2 doctors

\begin{tabular}{llll}
\hline Influencing factor & $\begin{array}{l}\text { Medical } \\
\text { students (n) }\end{array}$ & $\begin{array}{l}\text { FY2 } \\
\text { doctors (n) }\end{array}$ & p-value \\
\hline Specialties in FYI & 31.3 & 90.5 & 0.0001 \\
Specialties in FY2 & 48.5 & 98.8 & 0.0001 \\
Undergraduate experience & 23.3 & 20.2 & 0.378 \\
Prestige & 18.6 & 11.9 & 0.138 \\
Perceived competitiveness & 24.4 & 14.3 & 0.069 \\
Academic & 24.4 & 9.5 & 0.012 \\
Location & 194.2 & 164.3 & 0.034 \\
Family & 64.8 & 56.0 & 0.222 \\
Partner & 87.0 & 75.0 & 0.176 \\
Friends & 32.1 & 23.8 & 0.169 \\
Finance & 19.9 & 10.7 & 0.073 \\
Recommendations & 31.6 & 25.0 & 0.208 \\
\hline
\end{tabular}

Note: $p$-value (chi-square test $), C R S=(3 \times$ first factor $)+(2 \times$ second factor $)+$ third factor. Abbreviations: CRS, cumulative ranking score; FYI, foundation year I; FY2, foundation year-2.

and FY2 doctors, respectively, felt that it influenced/should influence the choice of foundation school. Partners were lower priorities for medical students than for FY2 doctors ( $52.1 \%$ vs $85.7 \%)$, as were friends ( $55.4 \%$ vs $76.2 \%)$.

With regard to specialties, only $43.5 \%$ of medical students compared with $79.8 \%$ of FY2 doctors strongly agreed, or agreed, that specialties in FY1 influenced their choice of foundation school. For specialties in FY2, these figures were $47.4 \%$ and $85.7 \%$, respectively. There was a statistically significant difference in the agreement of specialties between medical students and FY2 ( $p=0.001$; chi-square).

Availability of an academic position was important for $15.5 \%$ of medical students when selecting a foundation school. In relation to prestige, $40.2 \%$ of medical students and $38.1 \%$ of FY2 doctors were in agreement that it influenced/should influence the choice of foundation school. For perceived competitiveness, this figure was $52.9 \%$ and $44 \%$, respectively.

Undergraduate experience was felt to be important by $67.6 \%$ and $65.5 \%$ of medical students and FY2 doctors, respectively. Personal recommendations were important for $62.3 \%$ and $79.8 \%$ and finance for $43.8 \%$ and $71.4 \%$, respectively.

Also, $44 \%$ of medical students reported that geographic location was the most important factor influencing their choice of foundation school, the highest figure throughout all 12 choices. Using the CRS formula, the top three overall choices for final-year medical students were location (CRS=194.2), partner (CRS=87.0) and family (CRS=64.8).

A total of $34.5 \%$ of FY2 doctors said that location should be the most important factor influencing the choice of foundation school for medical students. The top three overall choices 
for FY2 doctors were location (CRS=164.3), specialties in FY2 (CRS=98.8) and specialties in FY1 (CRS=90.5).

When analyzing the differences in CRS for the top three most influencing factors between final-year medical students and FY2 doctors, two factors showed statistical significance in difference, namely, choice of specialties in FY1 $(p=0.0001$; chi-square) and FY2 ( $p=0.0001$; chi-square).

\section{Discussion}

Factors influencing the choice of foundation school are of great interest to numerous groups involved in the recruitment process of newly qualified doctors, including individual foundation schools, postgraduate trainers, applicants and medical schools. Our study demonstrates that geographic location and social factors primarily shape the route of early postgraduate training for British medical students.

FY2 doctors agree, more than medical students, that FY1 and FY2 specialties, academic jobs, partner and finance are important when applying to foundation schools. These data suggest that following 18 months of training, FY2 doctors begin to appreciate that the roles of academia and specialties experienced may help shape one's curriculum vitae or decide on their future specialty of choice. From a social aspect, it appears that FY2 doctors believe that their partner and financial factors are important. The majority of students appear to agree that location and undergraduate experience are important factors when selecting foundation schools. This is not surprising as undergraduates will have limited experience in the other influencing factors (specialties, academia, and finance).

Our study has demonstrated that location is the most important factor influencing undergraduate medical students in their choice of foundation school. This is in keeping with previous similar studies by Patel et $\mathrm{al}^{9}$ and McElvanna et al. ${ }^{10}$ Social relationships in the form of partner and family were second and third, respectively.

The actual specialties incorporated into foundation year programs appear to be less influential for medical students. This is in stark contrast to what would be advised by their senior peers who have experienced the foundation program. Our study highlights that medical students should be counseled with regard to taking greater consideration into the specialties they will be undertaking when selecting their foundation school. Medical students should be made aware that following location, the content of their 2-year training program is an important factor that should be taken into account. Unlike other significant factors, actual choice of specialties in the 2-year foundation program lies in the control of foundation schools. Individual foundation schools could potentially provide more flexibility in choice of specialties within the 2-year program to make their institutions more attractive to future applicants.

Our study has successfully confirmed which factors influence foundation school applicants on their choice of foundation school. Our study also explores which factors should be taken into account, with advice being obtained from those who have experienced the foundation program.

\section{Limitations}

There are several limitations inherent to this study. We had a low sample number of FY2 doctors, at only 84 who represented 8 out of the 21 foundations schools. This sample size may not represent the population for which the scale was intended, and there is a potential that our results may be subject to the influence of chance factors. Our study is also limited by the low response rate from undergraduate medical students (361/2092 [17.3\%]). All medical schools were invited to take part in our study; however, only nine out of the 32 UK medical schools agreed. Our low response rate could have been addressed with a second wave of emails or providing paper-based questionnaires. Our study had a superior number of participants compared to the two previous studies ${ }^{9,10}$ (361 vs 149 [response rate $\left.=61 \%\right]^{10}$ and 46 [response rate unknown $]^{9}$ ) and sampled of a greater percentage of medical schools $\left(9\right.$ vs $1^{10}$ and $\left.3^{9}\right)$. Nevertheless, further studies should include a greater participant number from a more comprehensive number of foundation/medical schools.

\section{Implications for medical education and workforce planning}

Our study suggests that if a particular foundation school wants to attract newly qualified medical graduates, then they should address location, social relationships and choices of specialties. Naturally, location is a constant that is unable to be altered. If individual foundation schools could provide a greater choice and flexibility of specialties within their 2-year program, they could potentially make their institution more attractive to future applicants. With regard to social relationships, an individual foundation school could alter their current linked application system to be more appealing for such applicants.

\section{Conclusion}

Our study suggests that location and social relationships are the key components to assisting a medical student in deciding upon their choice of foundation school. UK medical schools should make their foundation school applicants more aware 
of the importance of clinical specialties that will be undertaken during their future FY1 and FY2 years. If individual foundation schools could provide a more favorable linked application system and greater choice and flexibility of specialties within their 2-year program, they could potentially make their institution more attractive to future applicants.

\section{Acknowledgment}

The study participants were made aware that the collected data were intended for publication and presentation. Availability of data and material: all raw data are available on a cloud-based access system.

\section{Author contributions}

All of the authors designed the work, interpreted and analyzed the data, drafted the manuscript and revised it critically, approved the final version of the manuscript, and agree to be accountable for all aspects of the work.

\section{Disclosure}

The authors report no conflicts of interest in this work.

\section{References}

1. Hays R. Foundation programme for newly qualified doctors. $B M J$. 2005;331(7515):465-466.
2. Foster K. Medical school choice: what influences applicants? Clin Teach. 2014;11(4):307-10.

3. Kumar R, Dhaliwal U. Career choices of undergraduate medical students. Natl Med J India. 2011;24(3):166-169.

4. Du J, Sathanathan J, Naden G, Child S. A surgical career for New Zealand junior doctors? Factors influencing this choice. N Z Med J. 2009; 122(1300):29-37.

5. Saigal P, Takemura Y, Nishiue T, Fetters MD. Factors considered by medical students when formulating their specialty preferences in Japan: findings from a qualitative study. BMC Med Educ. 2007;7:31.

6. Soethout MB, Ten Cate TJ, van der Wal G. Factors associated with the nature, timing and stability of the specialty career choices of recently graduated doctors in European countries, a literature review. Med Educ Online. 2004;9(1)4360.

7. Yap C, Rosen S, Sinclair AM, Pearce I. What undergradaute factors influence medical students when making their choice of post graduate career? BJMSU. 2012;5(1):11-15.

8. Ibrahim M, Fanshawe A, Patel V, et al. What factors influence British medical students' career intentions? Med Teach. 2014;36(12):1064-1072.

9. Patel S, Colaco HB, Hossain FS. Factors influencing foundation programme choice among medical students. JRSM Short Rep. 2010;1(1):4.

10. McElvanna K, Boohan M, McKeown PP. Factors influencing final year medical students' choice of Foundation Programme. Ulster Med J. 2013; 82(3):141-145.

11. Kmietowicz Z. Seven in 10 junior doctors will leave NHS if new contract is imposed, survey finds. BMJ. 2015;351:h5642.

12. Taylor KS, Lambert TW, Goldacre MJ. Career progression and destinations, comparing men and women in the NHS: postal questionnaire surveys. BMJ. 2009; 338:b1735.

13. Cleland JA, Johnston PW, Anthony M, Khan N, Scott NW. A survey of factors influencing career preference in new-entrant and exiting medical students from four UK medical schools. BMC Med Educ. 2014;14:151.

14. Eysenbach G. Improving the quality of Web surveys: the Checklist for Reporting Results of Internet E-Surveys (CHERRIES). J Med Internet Res. 2004;6(3):e34.
Advances in Medical Education and Practice

\section{Publish your work in this journal}

Advances in Medical Education and Practice is an international, peerreviewed, open access journal that aims to present and publish research on Medical Education covering medical, dental, nursing and allied health care professional education. The journal covers undergraduate education, postgraduate training and continuing medical education

\section{Dovepress}

including emerging trends and innovative models linking education, research, and health care services. The manuscript management system is completely online and includes a very quick and fair peer-review system. Visit http://www.dovepress.com/testimonials.php to read real quotes from published authors. 